\title{
The national burden of orthopedic injury: Cross-sectional estimates for trauma system planning and optimization
}

\author{
Molly P. Jarman \\ Brigham and Women's Hospital, Boston, Massachusetts \\ Michael J. Weaver \\ Brigham and Women's Hospital, Boston, Massachusetts \\ Adil H. Haider \\ Aga Khan University, adil.haider@aku.edu \\ Ali Saleem \\ Brigham and Women's Hospital, Boston, Massachusetts \\ Mitchel B. Harris \\ Harvard Medical School, Boston, Massachusetts
}

Follow this and additional works at: https://ecommons.aku.edu/pakistan_fhs_mc_surg_surg

Part of the Orthopedics Commons, Surgery Commons, and the Trauma Commons

\section{Recommended Citation}

Jarman, M., Weaver, M., Haider, A. H., Saleem, A., Harris, M. (2020). The national burden of orthopedic injury: Cross-sectional estimates for trauma system planning and optimization. Journal of Surgical Research, 249, 197-204.

Available at: https://ecommons.aku.edu/pakistan_fhs_mc_surg_surg/801 


\title{
The National Burden of Orthopedic Injury: Cross- Sectional Estimates for Trauma System Planning and Optimization
}

\author{
Molly P. Jarman, PhD, ${ }^{a, b, *}$ Michael J. Weaver, $\mathrm{MD}, \mathrm{c}, d$ \\ Adil H. Haider, MD, ${ }^{a, e}$ Ali Salim, MD, ${ }^{a, b, f}$ and Mitchel B. Harris, $\mathbf{M D}^{d, g}$ \\ ${ }^{a}$ Center for Surgery and Public Health, Department of Surgery, Brigham and Women's Hospital, Boston, \\ Massachusetts \\ ${ }^{\mathrm{b}}$ Department of Surgery, Harvard Medical School, Boston, Massachusetts \\ ${ }^{\mathrm{c} D i v i s i o n}$ of Orthopaedic Trauma, Department of Orthopaedic Surgery, Brigham and Women's Hospital, Boston, \\ Massachusetts \\ d Department of Orthopaedic Surgery, Harvard Medical School, Boston, Massachusetts \\ ${ }^{\mathrm{e}}$ College of Medicine, Aga Khan University, Karachi, Pakistan \\ ${ }^{\mathrm{f}}$ Division of Trauma, Burns, and Surgical Critical Care, Department of Surgery, Brigham and Women's Hospital, \\ Boston, Massachusetts \\ ${ }^{g}$ Department of Orthopaedic Surgery, Massachusetts General Hospital, Boston, Massachusetts
}

\section{A R T I C L E I N F O}

\section{Article history:}

Received 18 October 2019

Received in revised form

26 November 2019

Accepted 2 December 2019

Available online $\mathrm{xxx}$

\section{Keywords:}

Orthopaedic trauma

Trauma systems

Injury

\begin{abstract}
A B S T R A C T
Background: Management of orthopedic injuries is a critical component of comprehensive trauma care. As patterns of injury incidence and recovery change in the face of emerging injury prevention efforts and technologies and an aging US population, assessment of the burden of orthopedic injury is essential to optimize trauma system planning. We sought to estimate the incidence of orthopedic injury requiring emergency orthopedic surgery in the United States. Methods: Using nationally representative samples from the Agency for Healthcare Research and Quality Healthcare Cost and Utilization Project, we estimated the incidence of orthopedic injury, polytrauma with orthopedic injury, and emergency operative orthopedic procedures performed for the management of traumatic injury. We used multivariable logistic regression to identify patient, injury, and hospital characteristics associated with odds of emergency orthopedic surgery.

Results: A total of 7,214,915 patients were diagnosed with orthopedic injury in 2013-2014, resulting in 1,167,656 emergency orthopedic surgical procedures. Fall-related injuries accounted for $51 \%$ of health care encounters and $61 \%$ of emergency orthopedic surgical procedures. Odds of emergency orthopedic surgery were 2.04 times greater for patients with polytrauma, compared with isolated orthopedic injury $(P<0.001)$.

Conclusions: The total burden or orthopedic injury in the United States is substantial, and there is considerable heterogeneity in demand for care and practice patterns in the orthopedic trauma community. Population-based trauma system planning and tailored care delivery models would likely optimize initial treatment, recovery, and health outcomes for orthopedic trauma patients.
\end{abstract} (c) 2020 Elsevier Inc. All rights reserved.

\footnotetext{
* Corresponding author. Department of Surgery, Harvard Medical School, One Brigham Circle, 1620 Tremont Street, STE 2-016, Boston, MA 02120. Tel.: +1 617-525-9286; fax: +1 617-525-7723.

E-mail address: mjarman@bwh.harvard.edu (M.P. Jarman). 0022-4804/\$ - see front matter (c) 2020 Elsevier Inc. All rights reserved. 


\section{Introduction}

\section{Background}

Injury is a leading cause of death and disability in the United States, resulting in more than 38 million potential life years lost each year. ${ }^{1}$ In response to the morbidity and mortality associated with injury, and improvements in clinical approaches for the treatment of severely injured patients during the 20th century, the United States health care system has moved toward increasingly more organized and standardized systems for the delivery of trauma care.,3 The field of orthopedic traumatology has evolved in parallel with the standardization of trauma care, ${ }^{4,5}$ providing specialized treatment of patients with severe multisystem injuries in addition to an orthopedic injury burden.

Early and effective orthopedic trauma care often determines the trajectory of long-term functional outcomes. This is accentuated as general trauma care has improved the probability of surviving severe injury. National injury surveillance programs monitor the distribution of injury incidence and mortality ${ }^{1,6}$; however, there are currently no national estimates of the overall incidence of orthopedic injury or associated use of orthopedic trauma services, thereby limiting efforts to measure the capacity of trauma systems to care of injured patients. As patterns of injury incidence and recovery change in the face of emerging injury prevention technologies (e.g., autonomous vehicles ${ }^{7}$ ), compounded by an aging US population, 8 a comprehensive assessment of the burden of orthopedic injury is essential to any future trauma system planning.

\section{Rationale}

To advance our understanding of the demand for orthopedic trauma care in the United States, we used nationally representative data from the Agency for Healthcare Research and Quality Healthcare Cost and Utilization Project (HCUP) to estimate the national burden of orthopedic injury, including total injury incidence, use of surgical services, and factors associated with operative intervention for patients with orthopedic injury.

\section{Materials and methods}

\section{Data source and population}

This study used existing, deidentified data and was determined to be exempt from continuing review by institutional review board. Estimates of the national incidence of orthopedic injury were derived from the 2013-2014 Agency for Healthcare Research and Quality HCUP Nationwide Inpatient Sample (NIS) ${ }^{9}$ and Nationwide Emergency Department Sample (NEDS). ${ }^{10}$ The NIS includes a $20 \%$ sample of all hospital admissions in the United States for each year examined, and the NEDS includes a $20 \%$ sample of all emergency department encounters for each year. Both samples are weighted to allow approximations of service use and diagnostic patterns for the entire US population, including estimation of national injury incidence and use of orthopedic trauma services. Weights are based on census region, hospital urban/rural location, teaching status, ownership (public, private/nonprofit, or private/for profit), and hospital bed size.

To estimate the national incidence of orthopedic injury and associated patterns of treatment, we identified all patients diagnosed with orthopedic injury during an emergency department encounter or urgent/emergent inpatient admission. Orthopedic injury diagnoses were identified based on International Classification of Disease, Ninth Revision, Clinical Modification (ICD9-CM) diagnosis codes, including diagnoses in the range 805.0-839.9 (excluding superficial injury and late effects of injury). We classified patients as having orthopedic trauma surgery or emergency fracture work if they had at least one ICD9-CM procedure code for a musculoskeletal operation (77.00-81.99) with a diagnosis-related group classification requiring the use of an operating room and a visit type coded as urgent/emergency, as coded in the HCUP data sets. Patients with only one diagnosis of orthopedic injury and no additional nonorthopedic injury diagnoses were classified as having an isolated orthopedic injury. Orthopedic injury patients with multiple orthopedic diagnoses or at least one nonorthopedic injury diagnosis (excluding superficial injuries) were classified as having polytrauma. Injury mortality was classified based on reported patient disposition, including death in the emergency department or in the hospital before discharge. Injury mechanisms were identified using ICD9-CM external cause of injury codes (eCodes) and mechanism categories defined by the US Centers for Disease Control and Prevention ${ }^{11}$ (Table 1). Charlson Comorbidity Score (CCI) and Injury Severity Score (ISS) were derived from ICD9-CM diagnosis codes using the ICD Programs for Injury Categorization module in Stata (StataCorp, College Station, TX). ${ }^{12}$ Patient demographic characteristics and hospital characteristics were derived from standard variables included in the NIS and NEDS data sets. ${ }^{9,10}$

\section{Statistical approach}

All analyses were completed in Stata/MP 14.2 using the 20132014 NIS and NEDS data sets. Using HCUP survey weights, we estimated the national incidence of emergency department encounters and inpatient admissions with at least one diagnosis for orthopedic injury and examined the distribution of inpatient operative and nonoperative treatment of orthopedic injury by patient demographic characteristics (age, sex, race/ ethnicity, urban/rural residence, and insurance status), health status (CCI), injury characteristics (ISS, polytrauma, and injury mechanism), and hospital characteristics (trauma center designation, teaching status, ownership status, urban/rural location, and Census region). We then used bivariable (unadjusted) and multivariable (adjusted) logistic regression models to identify factors associated with odds of urgent/emergency orthopedic operative intervention for injured patients. The multivariable regression model included age, sex, race/ ethnicity, urban/rural residence, insurance status, CCI, ISS, polytrauma, injury mechanism, hospital teaching status, ownership status, urban/rural location, and Census region. Finally, we estimated the total burden of orthopedic injury by 
Table 1 - CDC injury mechanism classification. ${ }^{11}$

Injury mechanism

Falls

Intentional or unintentional injuries caused by falling from any level (e.g., from standing, from stairs)

Transportation

Intentional or unintentional injury involving motor vehicles, bicycles, pedestrians, or other modes of transportation

\begin{tabular}{|c|c|c|}
\hline Machinery & $\begin{array}{l}\text { Intentional of unintentional injury involving machinery used in industrial } \\
\text { or occupational activities }\end{array}$ & E919.0-E919.9 \\
\hline Firearm & Intentional or unintentional injury from firearms of any type & E922.0-E922.9, E955.0-E955.4 \\
\hline Struck by/against & $\begin{array}{c}\text { Intentional or unintentional injury resulting from being struck by or } \\
\text { against an object or person (i.e., struck by falling object, assault by } \\
\text { unarmed person) }\end{array}$ & E916.0-E917.9 \\
\hline Overexertion & $\begin{array}{c}\text { Injury from repeated or sudden exposure to extreme forces (e.g., repetitive } \\
\text { stress injury, hyperextension) }\end{array}$ & E927.0-E927.9 \\
\hline Cut/pierce & $\begin{array}{l}\text { Intentional or unintentional injury by cutting or piercing with sharp } \\
\text { object (e.g., knives, blades, household tools) }\end{array}$ & E920.0-E920.9, E956.0-E956.9 \\
\hline Nature & $\begin{array}{l}\text { Injury resulting from exposure to natural elements, weather, phenomena, } \\
\text { and/or animals (e.g., excessive heat, earthquake, snake bite) }\end{array}$ & E900.0-E909.9, E928.0-E928.2, E958.3 \\
\hline Unclassified & $\begin{array}{l}\text { Any injury not otherwise described, excluding burns, drowning, poison, } \\
\text { and suffocation. }\end{array}$ & - \\
\hline
\end{tabular}

injury mechanism in terms of the total number of orthopedic injury patients with emergency department of inpatient encounters, the number of patients receiving orthopedic surgical intervention, the number diagnosed with polytrauma, and the number who died from their injuries.

\section{Results}

\section{Incidence of orthopedic injury}

From January 1, 2013, to December 31, 2014, there were an estimated 7,214,915 hospital encounters for the treatment of orthopedic injuries, with 5,657,995 (78.4\%) managed in emergency department settings without hospital admission. This calculation included patients who were discharged, those held for observation without admission, and those patients who were transferred to other acute care hospitals or died before admission. The distribution of age, sex, race, urban/ rural residence, comorbidities, and insurance status for emergency department encounters and inpatient admissions is presented in Table 2. Among emergency department encounters for orthopedic injury without subsequent inpatient admission, $30.4 \%$ of patients were adults aged $\geq 55 \mathrm{y}, 44.2 \%$ were female, $89.4 \%$ had no associated comorbid health conditions $(\mathrm{CCI}=0), 14.4 \%$ had polytrauma, and $48.1 \%$ had a fall as the primary injury mechanism. In contrast, $55.6 \%$ of the $1,556,920$ orthopedic trauma inpatients were aged $\geq 55,53.8 \%$ were female, $47.5 \%$ had at least on comorbid health condition (CCI $\geq 1$ ), $62.6 \%$ had ISS $\geq 9,34.1 \%$ had polytrauma, and $60.8 \%$ had a fall as their primary injury mechanism.

The distribution of hospital characteristics for emergency department and inpatient encounters is presented in Table 3. Among emergency department encounters for orthopedic injury without subsequent inpatient admission, 54.9\% occurred at a nonteaching hospital, and $71.7 \%$ took place at a public/government-owned hospital. Among inpatient admissions, $61.7 \%$ were at teaching hospitals (i.e., Academic Medical
Centers), and $73.2 \%$ were at private/nonprofit hospitals. Most (71.4\%) of these emergency department encounters occurred at level III/IV or nontrauma centers. Trauma center designation is not reported for inpatient encounters in the NIS.

\section{National burden of orthopedic injury}

Table 4 illustrates the distribution of the national burden of orthopedic injury by injury mechanism. Inpatient and emergency department encounters for orthopedic injury resulted in an estimated 1,279,776 urgent/emergency orthopedic surgical procedures, with $56 \%$ of all inpatient orthopedic injury patients receiving at least one operative intervention during their initial inpatient admission. The most common cause of orthopedic injury was falls, with an estimated 3,670,689 incidents requiring emergency department or inpatient care in 2013-2014. This number accounted for half (50.9\%) of all orthopedic injury patients. The proportion of patients with polytrauma was highest for injuries resulting from firearms (43\%) and transportation (43\%). The majority of polytrauma patients had one $(43.9 \%)$ or two $(39.7 \%)$ orthopedic trauma diagnoses. Orthopedic operative care was most common among patients with injuries resulting from firearms (35\%) and least common for patients injured by being struck by/ against an object (3\%) or overexertion (2\%). Injury mortality rates were highest for injuries resulting from firearms (34\%). The total estimated volume of orthopedic procedures performed during the 2-y study period was highest for fall-related injuries $(715,212$ procedures) and lowest for patients with injuries resulting from natural phenomena (e.g., natural disasters, encounters with wildlife; 5872 procedures).

\section{Use of operative orthopedic intervention}

Unadjusted and adjusted odds ratios (ORs) for factors associated with urgent/emergency operative management of orthopedic injury are presented in Table 5. Findings from the multivariable logistic regression model adjusting for age, sex, 
Table 2 - Distribution of demographic and injury characteristics for orthopedic injury patients by treatment setting.

\begin{tabular}{|c|c|c|}
\hline Measures & $\begin{array}{c}\text { Emergency } \\
\text { department, } n(\%)\end{array}$ & $\begin{array}{c}\text { Inpatient, } \\
n(\%)\end{array}$ \\
\hline \multicolumn{3}{|l|}{ Age (y) } \\
\hline$\leq 4$ & $266,389(4.7)$ & $20,920(1.3)$ \\
\hline $5-14$ & $1,061,453(18.8)$ & $41,680(2.7)$ \\
\hline $15-24$ & $807,177(14.3)$ & $92,320(5.9)$ \\
\hline $25-34$ & $639,287(11.3)$ & $98,775(6.3)$ \\
\hline $35-44$ & $528,739(9.3)$ & $92,100(5.9)$ \\
\hline $45-54$ & $634,878(11.2)$ & $148,785(9.6)$ \\
\hline $55-64$ & $631,588(11.2)$ & $197,210(12.7)$ \\
\hline$\geq 65$ & $1,088,358(19.2)$ & $865,035(55.6)$ \\
\hline \multicolumn{3}{|l|}{ Sex } \\
\hline Male & $3,158,280(55.8)$ & $719,560(46.2)$ \\
\hline Female & $2,499,449(44.2)$ & $837,115(53.8)$ \\
\hline \multicolumn{3}{|l|}{ Race/ethnicity $^{\dagger}$} \\
\hline White, non-Hispanic & - & $1,141,560(73.3)$ \\
\hline Black, non-Hispanic & - & $120,490(7.7)$ \\
\hline Hispanic & - & $131,820(8.5)$ \\
\hline Other & - & $163,050(10.5)$ \\
\hline \multicolumn{3}{|l|}{ Urban/rural residence } \\
\hline Rural & $1,137,570(20.2)$ & $287,260(18.6)$ \\
\hline Urban & $4,483,549(79.8)$ & $1,260,360(81.4)$ \\
\hline \multicolumn{3}{|l|}{ CCI } \\
\hline 0 & $5,058,058(89.4)$ & $817,810(52.5)$ \\
\hline 1 & $459,410(8.1)$ & $355,150(22.8)$ \\
\hline$\geq 2$ & $140,529(2.5)$ & $383,960(24.7)$ \\
\hline \multicolumn{3}{|l|}{ Insurance status } \\
\hline Private & $2,035,574(35.9)$ & $365,620(23.5)$ \\
\hline Medicare/Medicaid & $2,413,466(42.7)$ & $1,000,275(64.2)$ \\
\hline Uninsured & $1,208,956(21.4)$ & $191,025(12.3)$ \\
\hline \multicolumn{3}{|l|}{ Died } \\
\hline No & $5,653,284(99.9)$ & $1,517,515(97.5)$ \\
\hline Yes & $4712(0.1)$ & $39,405(2.5)$ \\
\hline \multicolumn{3}{|l|}{ ISS } \\
\hline $1-8$ & $3,335,696(94.3)$ & $581,885(37.4)$ \\
\hline $9-15$ & $294,364(5.2)$ & $797,070(51.2)$ \\
\hline $16-19$ & $15,112(0.3)$ & $69,605(4.5)$ \\
\hline $20+$ & $12,825(0.2)$ & $108,260(6.9)$ \\
\hline \multicolumn{3}{|l|}{ Polytrauma } \\
\hline No & $4,842,698(85.6)$ & $1,026,705$ (65.9) \\
\hline Yes & $815,298(14.4)$ & $530,215(34.1)$ \\
\hline \multicolumn{3}{|l|}{ Injury mechanism } \\
\hline Falls & $2,724,085(48.1)$ & $946,605(60.8)$ \\
\hline Transportation & $602,035(10.6)$ & $311,705(20.0)$ \\
\hline Machinery & $45,233(0.8)$ & $9340(0.6)$ \\
\hline Firearm & $13,785(0.2)$ & $22,510(1.4)$ \\
\hline Struck by/against & 787,278 (13.9) & $40,304(2.6)$ \\
\hline Overexertion & $305,215(5.4)$ & $11,515(0.7)$ \\
\hline \multirow[t]{2}{*}{ Cut/pierce } & $65,593(1.2)$ & $7600(0.5)$ \\
\hline & & (continued) \\
\hline
\end{tabular}

\section{Table 2 - (continued)}

\begin{tabular}{lcc} 
Measures & $\begin{array}{c}\text { Emergency } \\
\text { department, }\end{array}$ (\%) & $\begin{array}{c}\text { Inpatient, } \\
n(\%)\end{array}$ \\
\hline Nature & $21,227(0.4)$ & $7010(0.5)$ \\
Unclassified & $1,093,547(19.3)$ & $200,330(12.9)$ \\
\hline
\end{tabular}

"Emergency department patients without subsequent admission, including patients who died in the emergency department, were treated and held for observation or transferred to other medical facilities.

${ }^{\dagger}$ Race/ethnic information not included in HCUP NEDS database.

race/ethnicity, urban/rural residents, CCI, insurance status, ISS, mortality, polytrauma, injury mechanism, urban/rural hospital location, teaching status, hospital ownership, and Census region are described below.

Compared with patients aged 25-34 y and controlling for patient, injury, and hospital characteristics, the odds of operative orthopedic intervention were $74 \%$ less for patients $\leq 4$ y $(P<0.001), 49 \%$ more for patients aged $5-14$ y $(P<0.001)$, $13 \%$ more for patients aged $15-24$ y $(P<0.001), 16 \%$ less for patients aged $34-44$ y $(P<0.001), 39 \%$ less for patients aged 45 54 y $(P<0.001), 45 \%$ less for patients aged 55-64 y $(P<0.001)$, and $49 \%$ less for patients aged $\geq 65$ y $(P<0.001)$. Female patients were $34 \%$ more likely to receive operative care, controlling for other patient and hospital variables $(P<0.001)$. The incidence of surgical intervention (use of operative interventions) decreased with increasing number of comorbidities, with a $11 \%$ reduction in odds of operative intervention for patients with CCI of 1, compared with those without comorbidities $(P<0.001)$ and a $22 \%$ reduction in odds of intervention for patients with CCI $\geq 2(P<0.001)$. The odds of orthopedic operative intervention were $9 \%$ lower for urban residents, compared with rural residents $(P<0.001)$. Compared with patients with private insurance, those without health insurance were $4 \%$ less likely to have had an orthopedic operative intervention $(P<0.001)$, and those with Medicare/Medicaid as their primary insurance were 19\% less like to have an operative intervention $(P<0.001)$.

Controlling for patient, injury, and hospital characteristics, patients who died from their injuries/trauma burden were $67 \%$ less likely to have had an operative intervention for their orthopedic injury than those who survived to discharge $(P<0.001)$. Compared to patients with ISS $\leq 8$, the odds of operative intervention were 4.97 times higher for patients with ISS 9-15 $(P<0.001), 1.59$ time greater for patients with ISS 16-19 $(P<0.001)$, and 2.11 times greater for patients with ISS $\geq 20(P<0.001)$. Patients with polytrauma were 2.04 times more likely to have operative management of orthopedic injury than those without polytrauma $(P<0.001)$. Compared with injury with unclassified mechanisms, the odds of operative intervention were highest for patients with injuries resulting from encounters with machinery $(\mathrm{OR}=5.29$; $P<0.001)$ and falls $(O R=2.06 ; P<0.001)$.

After adjustment for patient, injury, and hospital characteristics, the odds of operative intervention were $19 \%$ higher at urban hospitals, compared with rural $(P<0.001)$. Compared with private/for-profit hospitals, the odds of operative intervention were $6 \%$ lower at private/nonprofit hospitals 
Table 3 - Distribution of facility characteristics for hospitals caring for orthopedic injury patients by treatment setting.

\begin{tabular}{|c|c|c|}
\hline Measures & $\begin{array}{c}\text { Emergency } \\
\text { department, } n(\%)\end{array}$ & $\begin{array}{c}\text { Inpatient, } \\
n(\%)\end{array}$ \\
\hline \multicolumn{3}{|l|}{ Trauma level ${ }^{\dagger}$} \\
\hline Level I/II & $1,615,953(28.6)$ & - \\
\hline Level III/IV/NTC & $4,042,043(71.4)$ & - \\
\hline \multicolumn{3}{|l|}{ Urban/rural hospital } \\
\hline Rural & $1,122,943(19.8)$ & 716,615 (33.7) \\
\hline Urban & $4,535,053(80.2)$ & $1,410,305(66.3)$ \\
\hline \multicolumn{3}{|l|}{ Teaching status } \\
\hline Teaching & $2,546,591(45.0)$ & $960,771(61.7)$ \\
\hline Nonteaching & $3,111,405(54.9)$ & $596,129(38.3)$ \\
\hline \multicolumn{3}{|l|}{ Ownership status } \\
\hline Private/nonprofit & $830,887(14.7)$ & 1,138,935 (73.2) \\
\hline Private/for profit & 772,995 (13.7) & $195,640(12.6)$ \\
\hline Public/government & $4,054,114(71.7)$ & $222,345(14.3)$ \\
\hline \multicolumn{3}{|l|}{ Census region } \\
\hline Northeast & $1,080,728(19.1)$ & 293,835 (18.9) \\
\hline Midwest & $1,345,266(23.8)$ & $337,850(21.7)$ \\
\hline South & $2,033,960(35.9)$ & $600,425(38.6)$ \\
\hline West & $1,198,042(21.2)$ & $324,990(20.9)$ \\
\hline
\end{tabular}

*Emergency department patients without subsequent inpatient admission, including patients who died in the emergency department, were treated and held for observation or transferred to other medical facilities.

Trauma center designation not available in NIS.

$(P<0.001)$ and 5\% lower at public/government-owned hospitals $(P<0.001)$. Compared with the Northeast census region, odds of operative intervention were $22 \%$ higher in the Midwest $(P<0.001)$, 34\% higher in the South $(P<0.001)$, and $25 \%$ higher in the West $(P<0.001)$.

\section{Discussion}

This study provides a national assessment of the incidence of orthopedic injury and demand for emergency operative management for such injuries. The epidemiology of injury has previously been described from the perspective of fatal injury, with particular focus on demographic and clinical factors contributing to injury mortality. ${ }^{13-17}$ Our estimates of emergency orthopedic surgical volume are consistent with previous estimates of the volume of orthopedic injury requiring intervention from and orthopedic traumatologists ${ }^{18}$ and provide additional context for orthopedic trauma workforce planning with additional estimates of the volume of emergency department and inpatient orthopedic injury patients who may require consultation from an orthopedic traumatology service without subsequent operative intervention. Our findings demonstrate a substantial burden of nonfatal orthopedic injuries, both in terms of the incidence of potentially debilitating injury and the health system requirements to properly manage these injuries. These findings can inform efforts for trauma system planning and resource allocation to ensure trauma care programs include adequate resources for the management of orthopedic injury.

Falls account for more than half of all orthopedic injury encounters in the United States. The proportions of fall patients with operative care or polytrauma are relatively low compared with other injury mechanisms, but the overall volume of these injuries places falls, as the most common injury mechanism requiring orthopedic trauma services and fracture care. This pattern is likely to persist and intensify over time as the proportion of the US population aged $\geq 65 \mathrm{y}$ is expected to increase from $15 \%$ in 2015 to an anticipated $23 \%$ by $2060 .{ }^{8}$ The incidence of orthopedic injury from falls highlights a need for integration of geriatric care in orthopedic trauma services as well as the growing need for primary fall prevention interventions in the aging population.

Other injury mechanisms, including motor vehicle collisions and firearm-related injuries, are associated with high rates of polytrauma and operative care. The overall volume of patients with these injuries is relatively low compared with those with fall-related injury, but the complexities of these injuries often require multiple operative interventions over the course of a patient's recovery. The burden of orthopedic injury from these mechanisms emphasizes the importance of organizational integration and/or communication between orthopedic and general surgical services to optimize care of severely injured patients with life-threatening orthopedic and nonorthopedic injuries.

Table 4 - Distribution of orthopedic injury incidence, polytrauma, mortality, emergency orthopedic operative care, and total emergency orthopedic procedure volume by injury mechanism.

\begin{tabular}{lccccc}
$\begin{array}{l}\text { Injury } \\
\text { Mechanisms }\end{array}$ & Incidence, \% $(n)$ & Polytrauma, \% $(n)$ & $\begin{array}{c}\text { Operative } \\
\text { intervention, \% }(n)\end{array}$ & $\begin{array}{c}\text { Mortality, \% }(n) \\
\text { Procedure } \\
\text { volume, \% }(n)\end{array}$ \\
\hline Falls & $50.9(3,670,689)$ & $47.9(644,185)$ & $65.7(601,742)$ & $55.2(72,050)$ & $55.7(715,212)$ \\
Transportation & $12.7(913,740)$ & $29.2(392,310)$ & $17.5(160,169)$ & $21.5(28,120)$ & $26.1(335,204)$ \\
Struck by/against & $11.4(827,583)$ & $6.6(88,360)$ & $2.5(23,253)$ & $2.0(2650)$ & $2.7(34,571)$ \\
Overexertion & $4.4(316,729)$ & $1.7(23,490)$ & $0.8(7586)$ & $0.4(480)$ & $0.8(9713)$ \\
Machinery & $0.8(54,572)$ & $0.7(9548)$ & $1.0(9384)$ & $0.2(250)$ & $1.4(17,924)$ \\
Cut/pierce & $1.0(73,193)$ & $0.6(8579)$ & $0.7(6415)$ & $1.6(2033)$ & $0.8(10,713)$ \\
Nature & $0.4(28,237)$ & $0.5(6928)$ & $0.4(3812)$ & $3.8(4912)$ & $0.5(5872)$ \\
Firearm & $0.5(36,295)$ & $1.2(15,755)$ & $1.4(12,779)$ & $9.5(12,356)$ & $1.9(25,069)$ \\
Unclassified & $17.9(1,293,877)$ & $11.6(156,359)$ & $9.9(90,340)$ & $5.9(7691)$ & $10.2(130,783)$ \\
\hline
\end{tabular}


Table 5 - Factors associated with urgent/emergent orthopedic operative care-unadjusted and adjusted odds of intervention.

\begin{tabular}{|c|c|c|c|c|c|c|}
\hline \multirow[t]{2}{*}{ Measures } & \multicolumn{3}{|c|}{ Unadjusted } & \multicolumn{3}{|c|}{ Adjusted } \\
\hline & OR & $95 \% \mathrm{CI}$ & $P$ & OR & $95 \% \mathrm{CI}$ & $P$ \\
\hline \multicolumn{7}{|l|}{ Age (reference: $25-34$ y) } \\
\hline$\leq 4 \mathrm{y}$ & 0.41 & $0.38-0.43$ & $<0.001$ & 0.26 & $0.24-0.28$ & $<0.001$ \\
\hline $5-14 y$ & 1.83 & $1.73-1.93$ & $<0.001$ & 1.49 & $1.40-1.58$ & $<0.001$ \\
\hline $15-24$ y & 1.13 & $1.09-1.18$ & $<0.001$ & 1.13 & $1.08-1.18$ & $<0.001$ \\
\hline $35-44$ y & 0.88 & $0.84-0.91$ & $<0.001$ & 0.84 & $0.80-0.88$ & $<0.001$ \\
\hline $45-54 y$ & 0.71 & $0.69-0.74$ & $<0.001$ & 0.61 & $0.58-0.63$ & $<0.001$ \\
\hline $55-64$ y & 0.78 & $0.76-0.81$ & $<0.001$ & 0.55 & $0.53-0.57$ & $<0.001$ \\
\hline$\geq 65 \mathrm{y}$ & 1.02 & $0.99-1.05$ & 0.25 & 0.51 & $0.49-0.53$ & $<0.001$ \\
\hline \multicolumn{7}{|l|}{ Sex (reference: male) } \\
\hline Female & 1.41 & $1.39-1.43$ & $<0.001$ & 1.34 & $1.32-1.37$ & $<0.001$ \\
\hline \multicolumn{7}{|c|}{ Race/ethnicity (reference: white) } \\
\hline African American & 0.87 & $0.85-0.90$ & $<0.001$ & 0.98 & $0.95-1.01$ & 0.20 \\
\hline Hispanic & 1.01 & $0.99-1.04$ & 0.41 & 1.08 & $1.05-1.11$ & $<0.001$ \\
\hline Other & 0.98 & $0.96-1.01$ & 0.18 & 1.03 & $0.99-1.05$ & 0.060 \\
\hline \multicolumn{7}{|c|}{ Urban/rural residence (reference: rural) } \\
\hline Urban & 0.96 & $0.95-0.98$ & $<0.001$ & 0.91 & $0.89-0.93$ & $<0.001$ \\
\hline \multicolumn{7}{|l|}{ CCI (reference: CCI = 0) } \\
\hline 1 & 0.96 & $0.94-0.98$ & $<0.001$ & 0.89 & $0.87-0.91$ & $<0.001$ \\
\hline$\geq 2$ & 0.84 & $0.82-0.85$ & $<0.001$ & 0.78 & $0.77-0.79$ & $<0.001$ \\
\hline \multicolumn{7}{|c|}{ Insurance status (reference: private) } \\
\hline Medicare/Medicaid & 1.05 & $1.03-1.07$ & $<0.001$ & 0.81 & $0.79-0.83$ & $<0.001$ \\
\hline Uninsured & 0.98 & $0.95-1.01$ & 0.06 & 0.96 & $0.93-0.98$ & $<0.001$ \\
\hline \multicolumn{7}{|l|}{ Died (reference: no) } \\
\hline Yes & 0.31 & $0.29-0.32$ & $<0.001$ & 0.33 & $0.32-0.35$ & $<0.001$ \\
\hline \multicolumn{7}{|l|}{ ISS (reference: ISS 1-8) } \\
\hline $9-15$ & 4.27 & $4.20-4.34$ & $<0.001$ & 4.97 & $4.88-5.06$ & $<0.001$ \\
\hline $16-19$ & 0.99 & $0.95-1.02$ & 0.44 & 1.59 & $1.52-1.65$ & $<0.001$ \\
\hline $20+$ & 1.15 & $1.12-1.18$ & $<0.001$ & 2.11 & $2.04-2.18$ & $<0.001$ \\
\hline \multicolumn{7}{|c|}{ Polytrauma (reference: no) } \\
\hline Yes & 1.85 & $1.82-1.88$ & $<0.001$ & 2.04 & $2.00-2.08$ & $<0.001$ \\
\hline \multicolumn{7}{|c|}{ Injury mechanism (reference: unclassified) } \\
\hline Fall & 2.36 & $2.30-2.40$ & $<0.001$ & 2.06 & $2.01-2.11$ & $<0.001$ \\
\hline Transportation & 1.46 & $1.42-1.49$ & $<0.001$ & 1.26 & $1.22-1.30$ & $<0.001$ \\
\hline Machinery & 4.25 & $3.83-4.73$ & $<0.001$ & 5.29 & 4.73-5.92 & $<0.001$ \\
\hline Firearm & 1.75 & $1.64-1.86$ & $<0.001$ & 0.97 & $0.90-1.04$ & 0.39 \\
\hline Struck by/against & 1.43 & $1.36-1.50$ & $<0.001$ & 1.26 & $1.20-1.34$ & $<0.001$ \\
\hline Overexertion & 2.33 & $2.14-2.54$ & $<0.001$ & 2.13 & $1.94-2.34$ & $<0.001$ \\
\hline Cut/pierce & 1.82 & $1.64-2.01$ & $<0.001$ & 1.94 & $1.74-2.17$ & $<0.001$ \\
\hline Nature & 1.40 & $1.26-1.56$ & $<0.001$ & 1.42 & $1.27-1.61$ & $<0.001$ \\
\hline \multicolumn{7}{|c|}{ Urban/rural hospital (reference: rural) } \\
\hline Urban & 0.97 & 0.94-0.99 & 0.006 & 1.19 & $1.15-1.24$ & $<0.001$ \\
\hline \multicolumn{7}{|c|}{ Teaching status (reference: nonteaching) } \\
\hline Teaching & 1.13 & $1.12-1.15$ & $<0.001$ & 0.99 & $0.97-1.01$ & 0.45 \\
\hline \multicolumn{7}{|c|}{ Ownership status (private/for profit) } \\
\hline Private/nonprofit & 1.04 & $1.02-1.07$ & $<0.001$ & 0.94 & $0.91-0.96$ & $<0.001$ \\
\hline Public/government & 0.93 & $0.91-0.95$ & $<0.001$ & 0.95 & $0.93-0.98$ & $<0.001$ \\
\hline \multicolumn{7}{|c|}{ Census region (reference: Northeast) } \\
\hline & & & & & & intinued) \\
\hline
\end{tabular}


Table 5 - (continued)

\begin{tabular}{|c|c|c|c|c|c|c|}
\hline \multirow[t]{2}{*}{ Measures } & \multicolumn{3}{|c|}{ Unadjusted } & \multicolumn{3}{|c|}{ Adjusted } \\
\hline & OR & $95 \%$ CI & $P$ & OR & $95 \%$ CI & $P$ \\
\hline Midwest & 1.10 & $1.07-1.12$ & $<0.001$ & 1.22 & $1.19-1.25$ & $<0.001$ \\
\hline South & 1.25 & $1.22-1.27$ & $<0.001$ & 1.34 & $1.31-1.37$ & $<0.001$ \\
\hline West & 1.19 & $1.17-1.22$ & $<0.001$ & 1.25 & $1.22-1.29$ & $<0.001$ \\
\hline
\end{tabular}

$\mathrm{CI}=$ confidence interval.

Our analysis also identified a number of factors associated with the management of orthopedic injury using emergency operative interventions versus management with nonoperative care or delayed (relatively elective) operative interventions. Controlling for injury mechanism, patient demographics, and hospital characteristics, emergency operative management of orthopedic injury was less common for older patients and those with comorbid health conditions and more common for patients with higher injury severity and/or polytrauma. These patterns suggest a trend toward emergency operative management of orthopedic injuries that threaten life or limb, combined with use of nonoperative management for patients who are not likely to benefit from operative interventions (i.e., those who are likely to die regardless of orthopedic surgical care because of nonorthopedic injury and/or comorbid health conditions). Urban hospital location, for-profit hospital ownership, and locations outside of the Northeastern United States were also associated with higher odds of emergency operative intervention, suggesting that geographic and organization factors contribute to the timing and use of orthopedic trauma services.

\section{Limitations}

There are several limitations to note when interpreting these findings. We used national representative data designed to produce "big picture" estimates of incidence and treatment patterns. These data do not support estimates for geographic divisions smaller than US Census regions, limiting the generalizability of these estimates for regional trauma system planning; however, the associations between hospital characteristics and the use of orthopedic trauma services can inform future studies at the state and trauma service area level. The HCUP NIS data set does not include trauma center designations and the association between trauma center designation and operative intervention could not be examined in nationally representative data. The HCUP NEDS data do include trauma center designation for emergency department encounters, and our estimates indicate that the majority of emergency department encounters for orthopedic injury occur at Level III/IV centers or nontrauma centers. It is not clear how the distribution of trauma center designation for emergency department encounters may translate to inpatient admissions and future studies using state and/or regional data with trauma center designation should examine variation in orthopedic injury care by trauma center status. Finally, there are no clear guidelines for the identification of orthopedic trauma based on diagnosis codes in administrative data. We developed an ad hoc definition of orthopedic trauma accounting for anatomic injury location, total injury burden, and timing of operative intervention to capture the full scope of injuries that are likely to be treated by orthopedic traumatologists. Leaders in the field of orthopedic trauma care should work with health services researchers to develop standard definitions of orthopedic trauma for use when assessing orthopedic trauma care in administrative claims data.

\section{Conclusion}

The total burden or orthopedic injury in the United States is substantial with nearly one million hospital encounters each year. Fall-related injuries account for more than half of all orthopedic injury diagnoses requiring hospital admission, and the total burden of orthopedic injury is likely to increase as the US population of older adults continues to grow. Despite the prevailing incidence of falls, there is considerable heterogeneity in demand for care and practice patterns in the orthopedic trauma community, highlighting the need for population-based trauma system planning and tailored care delivery models.

\section{Acknowledgment}

Authors' contributions: M.J. contributed to the study design, data acquisition, analysis, interpretation of data, and drafting of this work. M.W. contributed to the study design and critical revision of this work. A.H. contributed to the conception of this study, data acquisition, interpretation of data, and critical revision of this work. A.S. contributed to interpretation of the data and critical revision of this work. M.H. contributed to the conception of this study, data acquisition, interpretation of data, and critical revision of this work.

This work was supported by a grant from the Center for Orthopaedic Trauma Advancement.

\section{Disclosure}

Each author certifies that he or she has no commercial associations (e.g., consultancies, stock ownership, equity interest, patent/licensing arrangements, etc) that might pose a conflict of interest in connection with the submitted article. 


\section{R E F E R E N C E S}

1. United States Centers for Disease Control and Prevention. Injury Prevention \& Control: Data \& Statistics (WISQARSTM); 2016. Available at: http://www.cdc.gov/injury/wisqars/. Accessed November 8, 2016.

2. Eastman AB, Mackenzie EJ, Nathens AB. Sustaining a coordinated, regional approach to trauma and emergency care is critical to patient health care needs. Health Aff (Millwood). 2013;32:2091-2098.

3. National Academy of Sciences, Committee on Trauma and Committee on Shock. Accidental Death and Disability: the Neglected Disease of Modern Society. Washington, DC: National Academies Press; 1966.

4. Distefano MC. Historical account of the OTA. Available at: https://ota.org/about-ota/history/historical-account-ota. Accessed March 13, 2019.

5. American College of Surgeons, Committee on Trauma. Resources for Optimal Care of the Injured Patient. Chicago, IL: American College of Surgeons, Committee on Trauma; 1990:79. iii.

6. United States Centers for Disease Control and Prevention. Multiple cause of death 1999-2016 Atlanta, GA. Available at: https://wonder.cdc.gov/wonder/help/mcd.html. Accessed November 28, 2018.

7. Kalra N, Groves DG. The Enemy of Good: Estimating the Cost of Waiting for Nearly Perfect Automated Vehicles. Santa Monica, CA: RAND; 2017:39. xiii.

8. United States Census Bureau. National Population Projections Tables; 2017. Washington, DC: United States Census Bureau; 2017. Available at: https://www.census.gov/data/tables/2017/ demo/popproj/2017-summary-tables.html. Accessed December 7, 2018.
9. Agency for Healthcare Research and Quality. NIS database documentation. Washington, DC. Available at: https://www. hcup-us.ahrq.gov/db/nation/nis/nisdbdocumentation.jsp. Accessed March 13, 2019.

10. Agency for Healthcare Research and Quality. NEDS database documentation. Washington, DC. Available at: https://www. hcup-us.ahrq.gov/db/nation/neds/nedsdbdocumentation.jsp. Accessed November 14, 2018.

11. Recommended framework for presenting injury mortality data. MMWR Recomm Rep. 1997;46:1-30.

12. Clark DE, Osler TM, Hahn DR. ICDPIC: Stata Module to Provide Methods for Translating International Classification of Diseases (Ninth Revision) Diagnosis Codes into Standard Injury Categories and/or Scores; 2010. Available at: https://ideas.repec.org/c/boc/ bocode/s457028.html. Accessed December 4, 2016.

13. Kaji AH, Bosson N, Gausche-Hill M, et al. Patient outcomes at urban and suburban Level I versus Level II trauma centers. Ann Emerg Med. 2017;70:161-168.

14. Jarman MP, Castillo RC, Carlini AR, Kodadek LM, Haider AH. Rural risk: geographic disparities in trauma mortality. Surgery. 2016;160:1551-1559.

15. Haider AH, Weygandt PL, Bentley JM, et al. Disparities in trauma care and outcomes in the United States: a systematic review and meta-analysis. J Trauma Acute Care Surg. 2013;74:1195-1205.

16. Ali MT, Hui X, Hashmi ZG, et al. Socioeconomic disparity in inpatient mortality after traumatic injury in adults. Surgery. 2013;154:461-467.

17. Haider AH, Chang DC, Efron DT, Haut ER, Crandall M, Cornwell 3rd EE. Race and insurance status as risk factors for trauma mortality. Arch Surg. 2008;143:945-949.

18. Clement RC, Carr BG, Kallan MJ, Reilly PM, Mehta S. Who needs an orthopedic trauma surgeon? An analysis of US national injury patterns. J Trauma Acute Care Surg. 2013;75:687-692. 